\title{
The ROS-generating oxidase Nox1 is required for epithelial restitution following colitis
}

\author{
Masayoshi KATO ${ }^{1)}$, Masaya MARUMO ${ }^{1)}$, Jun NAKAYAMA ${ }^{2)}$, Misaki MATSUMOTO ${ }^{3)}$, \\ Chihiro YABE-NISHIMURA ${ }^{3)}$, and Tohru KAMATA ${ }^{1)}$ \\ 1) Department of Molecular Biology and Biochemistry, Shinshu University Graduate School of Medicine, 3-1-1 \\ Asahi, Matsumoto, Nagano 390-8621, Japan \\ 2) Department of Molecular Pathology, Shinshu University Graduate School of Medicine, 3-1-1 Asahi, Matsumoto, \\ Nagano 390-8621, Japan \\ 3) Department of Pharmacology, Kyoto Prefectural University of Medicine, Kyoto 602-8566, Japan
}

\begin{abstract}
Accumulating evidence suggests that reactive oxygen species (ROS) generated by endogenous metabolic enzymes are involved in a variety of intracellular mechanisms. In particular, superoxide-generating NADPH oxidase (Nox) 1 is highly expressed in the colon and has been implicated in physiological and pathophysiological states of colon tissues. However, its role in tissue repair following colitis has not been fully elucidated. Our study using experimental colitis in mice showed that repair of the mucosal layer did not occur in Nox1-deficient mice following dextran sulfate sodium-induced colitis. This was accompanied by inhibition of proliferation, cell survival, migration, and terminal differentiation (generation of goblet cells) of crypt progenitor cells, as determined by histochemical analyses. Furthermore, Nox1 expression as well as ROS production in the colon crypt was increased during the repair process, and Nox1 deficiency suppressed these events. The results suggest that Nox1 promotes colon mucosal wound repair by sustaining the bioactivity of crypt progenitor cells and plays a crucial role in the epithelial restitution in the case of damage associated with colitis.
\end{abstract}

Key words: colitis, epithelial restitution, NADPH oxidase (Nox) 1, reactive oxygen species (ROS)

\section{Introduction}

NADPH oxidase (Nox) is a multi-subunit enzyme composed of transmembrane catalytic parts, Nox and p22phox, associated with several cytosolic regulatory subunits. Nox isoforms constitute a family composed of Nox1 5 and Duox 1 and 2 [12]. Noxs catalyze ROS generation in a tightly regulated manner and represents a major cellular source of ROS. In particular, Nox1-derived ROS modulate signaling events involved in growth, differentiation, and apoptosis in a variety of non-phagocytic tissues [11]. Nox1 has also been implicated in the pathogenesis of hypertension [16] and inflammatory pain [5]. As for colon bioactivity, Nox1 is highly expressed in the human and mouse colon epithelium [3, 8], and Nox1-generated ROS have been postulated to play a role in events such as host defense against luminal microorganisms, although its exact physiological role remained enigmatic.

In the colon epithelium, the stem cells self-renew, producing precursor cells in the lower part of crypt, and transit-precursor cells subsequently differentiate into colonocytes and secretory cells forming the surface epithelium [25]. Stem cells not only self-renew through-

(Received 23 December 2015 / Accepted 17 January 2016 / Published online in J-STAGE 15 February 2016)

Address corresponding: T. Kamata, Department of Molecular Biology and Biochemistry, Shinshu University Graduate School of Medicine, 3-1-1

Asahi, Matsumoto, Nagano 390-8621, Japan

New affiliation: Department of Tumor and Cellular Biochemistry, Faculty of Medicine, University of Miyazaki, Miyazaki 889-1601, Japan

C2016 Japanese Association for Laboratory Animal Science 
out life but also contribute to the repair of damaged tissue upon injury. A recent study using Nox1-deficient mice reported that Nox 1 controls proliferation and differentiation of progenitor cells in the normal colon that integrate $W n t / \beta$ catenin and Notch1 signaling [2]. This finding suggested a novel role of Nox 1 in colon homeostasis. However, the study did not provide direct evidence for the role of Nox1 in pathological states associated with epithelial injury and acute/chronic colitis. More recently, new data demonstrated that Nox 1 regulates epithelial cell migration, one of the initial responses to colon injury. Nox 1 was found to be coupled to the epithelial $\mathrm{N}$-formyl peptide receptor (FPR) system in the colon and to thereby mediate a FPR ligand-stimulated motility of colon cells, promoting mucosal wound repair [14]. Furthermore, combined deletion of Nox 1 and IL-10 recapitulated the features of human ulcerative colitis by affecting ER stress in goblet cells [26]. These observations raise the possibility that Nox 1-generated ROS play a critical role in maintenance of the colon mucus barrier as well as in rebuilding of the injured colon epithelium.

In the present study, we investigated the role of Nox 1 in the repair processes of the colon epithelium following colitis with a special focus on the status of proliferation and differentiation of crypt progenitor cells. No study so far has addressed these aspects of the Nox1-mediated healing process in the inflamed colonic mucosa. Our study using in vivo experimental colitis revealed that Nox1 participates in control of proliferation, anti-apoptotic activity, migration, and terminal differentiation of progenitor cells, thereby contributing to repair from mucosal injury.

\section{Materials and Methods}

\section{Animals}

Generation and characterization of $\operatorname{Noxl}^{-/ Y}\left(\mathrm{Nox} 1^{\mathrm{KO}}\right)$ mice were previously described [16]. Nox $1^{-/ Y}$ mice were backcrossed into the C57BL/6 genetic background for at least 16 generations. Mice were housed under a standard day/night cycle with free access to food and water. Experiments were performed using 5 to 12 mice per group. All experiment procedures were approved by the Experimental Animal Research Committee of the Shinshu University School of Medicine.

\section{Antibodies and reagents}

Dextran sulfate sodium salt (DSS: molecular mass,
36-50 kDa) was purchased from MP Biochemicals (Santa Ana, CA, USA), DPI was purchased from Calbiochem (San Diego, CA, USA), Hydro-CY3 (commercial name: ROS 550) was purchased from LI-COR Biosciences (Lincoln, NB, USA), and BrdU was purchased from Sigma-Aldrich (St. Louis, MO, USA). A TUNEL assay kit was purchased from Roche Applied Science (Manheim, Germany). The following antibodies were used: rabbit anti-Cox-2 from Cayman Chemicals (Ann Arbor, MI, USA), rabbit anti-HSP70 from Enzo Life Sciences (Villeurbanne, France), mouse anti-BrdU from Sigma-Aldrich, rabbit anti-Mucin 2 from Santa Cruz Biotechnology (Dallas, TX, USA), mouse anti-Ki-67 (BD Biosciences, San Jose, CA, USA), and mouse antiIкB $\alpha$ and, rabbit anti-phospho Erk Tyr-204/Thr-202 from Cell Signaling Technology (Danvers, MA, USA). Mouse monoclonal anti-Nox 1 antibodies were provided by Dr. D. Lambeth, who produced the antibodies through collaboration with diaDexus (South San Francisco, CA, USA).

\section{Induction of colitis}

Mice deficient in $\mathrm{Noxl}^{-/ Y}$ and wild type (WT) littermates received 2\% (wt $/ \mathrm{vol})$ DSS in drinking water for 4 days, and the DSS was withdrawn to allow recovery from colitis for an additional 5 days. In DPI treatment, NoxI $1^{-/ Y}$ and WT mice received both 2\% DSS in drinking water for 4 days and a daily intraperitoneal injection of DPI $(0.08 \mathrm{mg} / \mathrm{kg} /$ day $)$. The control group received DMSO. Mice were then allowed recovery as described above. Mice were sacrificed on day 9, and colons were removed and processed for histological and biochemical analyses. DSS-administered animals were monitored clinically for blood in stool and diarrhea.

\section{Histological analysis}

Colon tissue samples were fixed in $10 \%$ formalin, embedded in paraffin, deparaffinized, and retrieved as described previously [4]. The colon sections were immunostained with various antibodies by using second antibodies conjugated with horseradish peroxidase (Nichirei Biosciences Inc., Tokyo, Japan). Peroxidase activity was visualized using 3,3'-diaminobenzidine tetrahydrochloride (Nacalai Tesque, Inc., Kyoto, Japan). Counterstaining was performed with hematoxylin and eosin (H \& E). Alcian Blue (pH2.5)/periodic acid-Schiff base (AB-PAS) staining was used for detection of sugar chains attached to glycoproteins. Histochemical and 
biochemical analyses were performed in at least three separate experiments. A group of five WT mice and a group of five $\mathrm{Noxl}^{-/ Y}$ mice were used for each experiment. At least three colon sections were analyzed, with at least three images examined for each. Twenty crypts/ colon were counted in analyses of histochemical damage, goblet cell damage, and BrdU/Ki-67 staining. Colon crypt damage was evaluated by the presence of leukocyte recruitment/infiltration, thickening of the colon wall, and loss or immaturity of goblet cells, as described previously [21].

\section{Measurement of ROS generation}

Colons were dissected, washed three times with Hanks' balanced salt solution (HBSS), and labeled with $25 \mu \mathrm{M}$ Hydro-CY3 in HBSS at $37^{\circ} \mathrm{C}$ for $30 \mathrm{~min}$. Labeled colon tissues were fixed in $3.7 \%$ paraformaldehyde, sectioned, and mounted with $1 \mathrm{mg} / \mathrm{ml} \mathrm{p}$-phenylenediamine (Nacalai Tesque, Inc., Kyoto, Japan) in PBS/ glycerol. Fluorescence was analyzed by confocal microscopy with the excitation source at $514 \mathrm{~nm}$ and an emission wavelength of $543 \mathrm{~nm}$. The histogram was analyzed as described previously [19].

\section{Immunoblotting}

Colon tissues were homogenized in RIPA buffer by using a Teflon homogenizer, and lysates were subjected to immunoblotting analysis after clarification by centrifugation as described previously [10].

\section{Statistics}

Data represent the mean $\pm \mathrm{SD}$ of at least three separate experiments. Differences or correlations between two groups were assessed by Student's $t$ test. Differences with values of $P<0.05$ were considered to be statistically significant.

\section{Results}

Nox1 deficiency affects mucosal restitution following colitis

To address the functional role of Nox 1 in colon homeostasis, we used a mouse model of colon injury and inflammation induced by oral administration of DSS, which is known to be toxic to the colon epithelium [22]. The original assay protocol recommends that the $3-10 \%$ DSS phase is $6-10$ days long, followed by $6-10$ days recovery [22]. In our experiments, however, this condi- tion seemed to be too harsh, and more than half of the mice died. We therefore modified the protocol so that DSS treatment could be tolerated by the majority of the mice. Thus, WT mice were given 2\% DSS in drinking water for 4 days and recovered with normal drinking water for 5 days. Mice displayed clinical signs such as colonic bleeding and diarrhea at day 4 after administration of DSS. This was stopped by subsequent water intake, but histological analyses showed some remains of epithelial injury (Fig. 1A), confirming partial recovery from DSS-induced colitis as described previously [14]. Then, WT and Noxl $^{-/ Y}$ were treated with DSS under the same conditions as described above. Histological analyses revealed more severe epithelial injury in $\mathrm{Noxl}^{-/ Y}$ mice compared with the WT controls: the number of intact crypts in Noxl $^{-/ Y}$ mice was significantly smaller than that in WT mice (Fig. 1B). Injection of DPI, a general inhibitor of Nox isozymes, similarly decreased the number of restored crypts compared with DPI-untreated mice (Fig. 1C). Taken together, these data are consistent with a role of Nox 1 in mediating the process of crypt restoration.

We next examined the expression status of inflammation-related proteins. The level of a pro-inflammatory protein, Cox-2, expressed in mostly infiltrating leukocytes was higher in the colon from Nox $1^{-/ Y}$ mice than its WT counterpart (Figs. 1D and 1E). The NFkB pathway targeting genes encoding pro-inflammatory cytokines and chemokines also remained more active in $\operatorname{Nox}^{-/ Y}$ mice compared with WT mice, as indicated by a decrease in the level of IкB (Fig. 1E). The expression of a heatshock protein HSP72, a cytoprotective factor, was also compromised in the colon epithelium of $N_{x} \mathrm{I}^{-/ Y}$ mice (Fig. 1E). These data implicate that DSS-induced inflammatory responses remained more persistently in $\mathrm{Noxl}^{-/ Y}$ mice compared with WT mice. Thus, we conclude that Nox1 deficiency leads to impaired recovery from colon epithelial injury following withdrawal of DSS.

\section{Nox1 promotes both proliferation and migration of crypt progenitor cells}

Because our results indicated that dysfunction of Nox 1 leads to impaired restoration of the injured colon, we investigated whether Nox 1 deficiency affects proliferation of crypt progenitor cells during recovery from colitis. To this end, the proliferation of colonic crypt cells was examined by analyzing the expression of Ki-67, a cell proliferation-associated marker, after 5 days of re- 

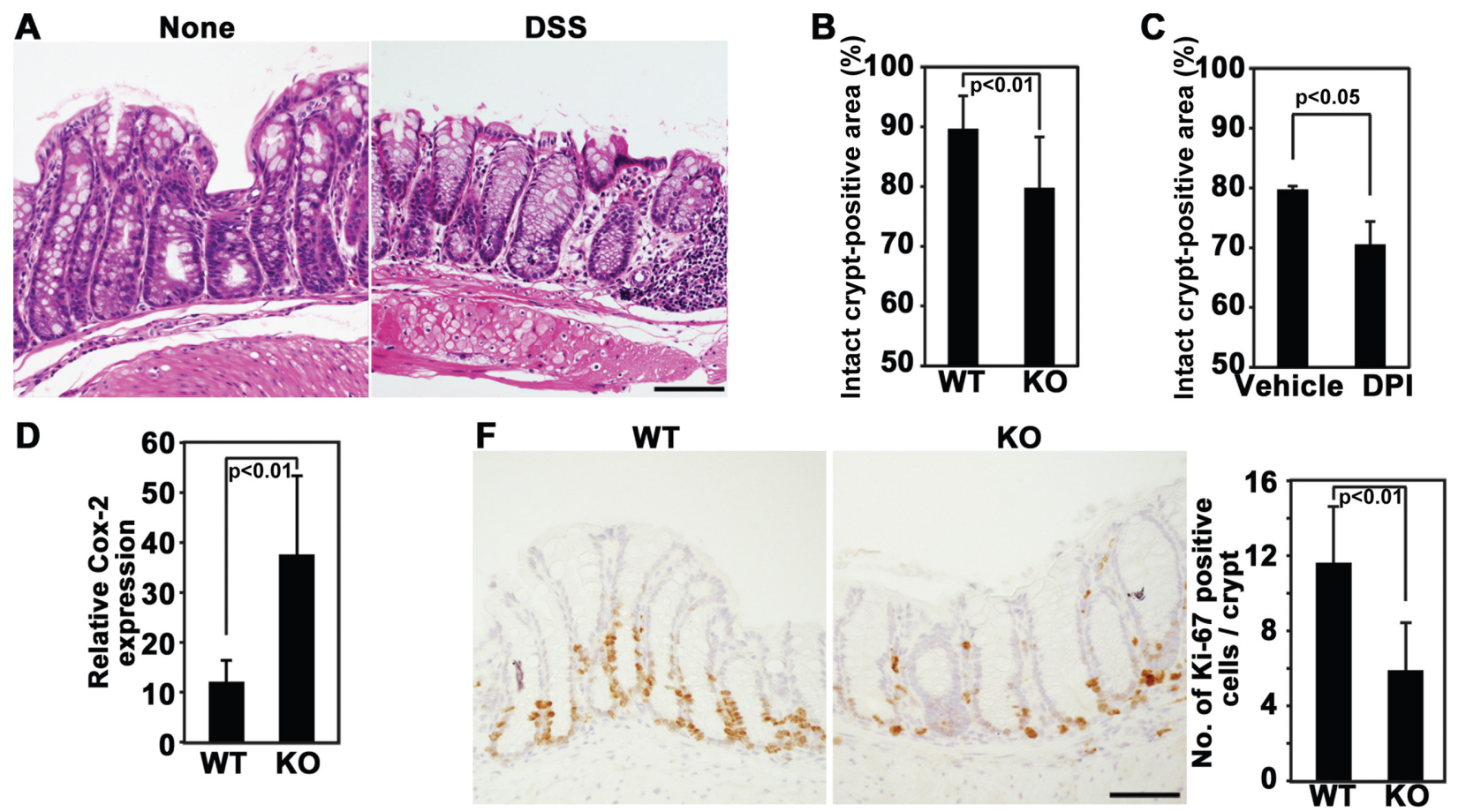

E

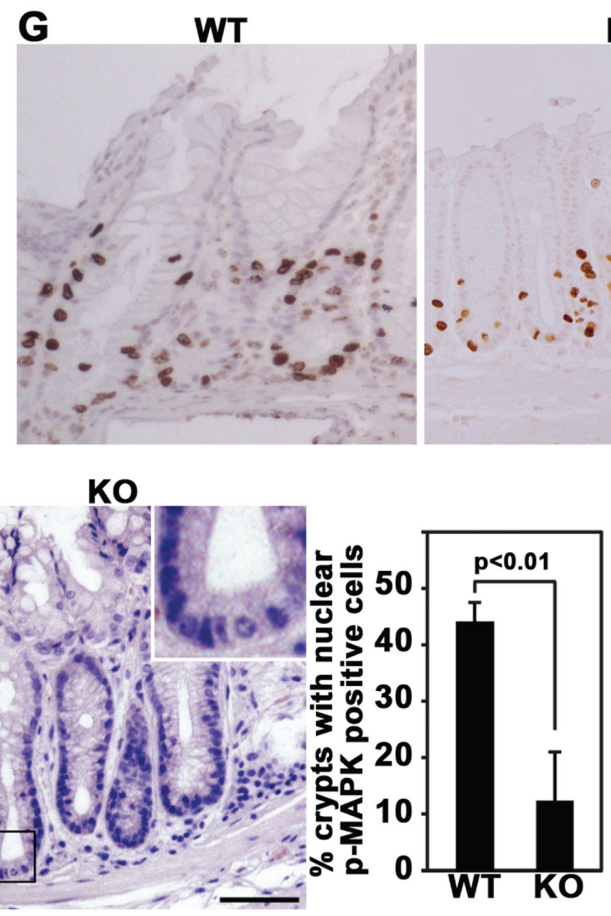

KO
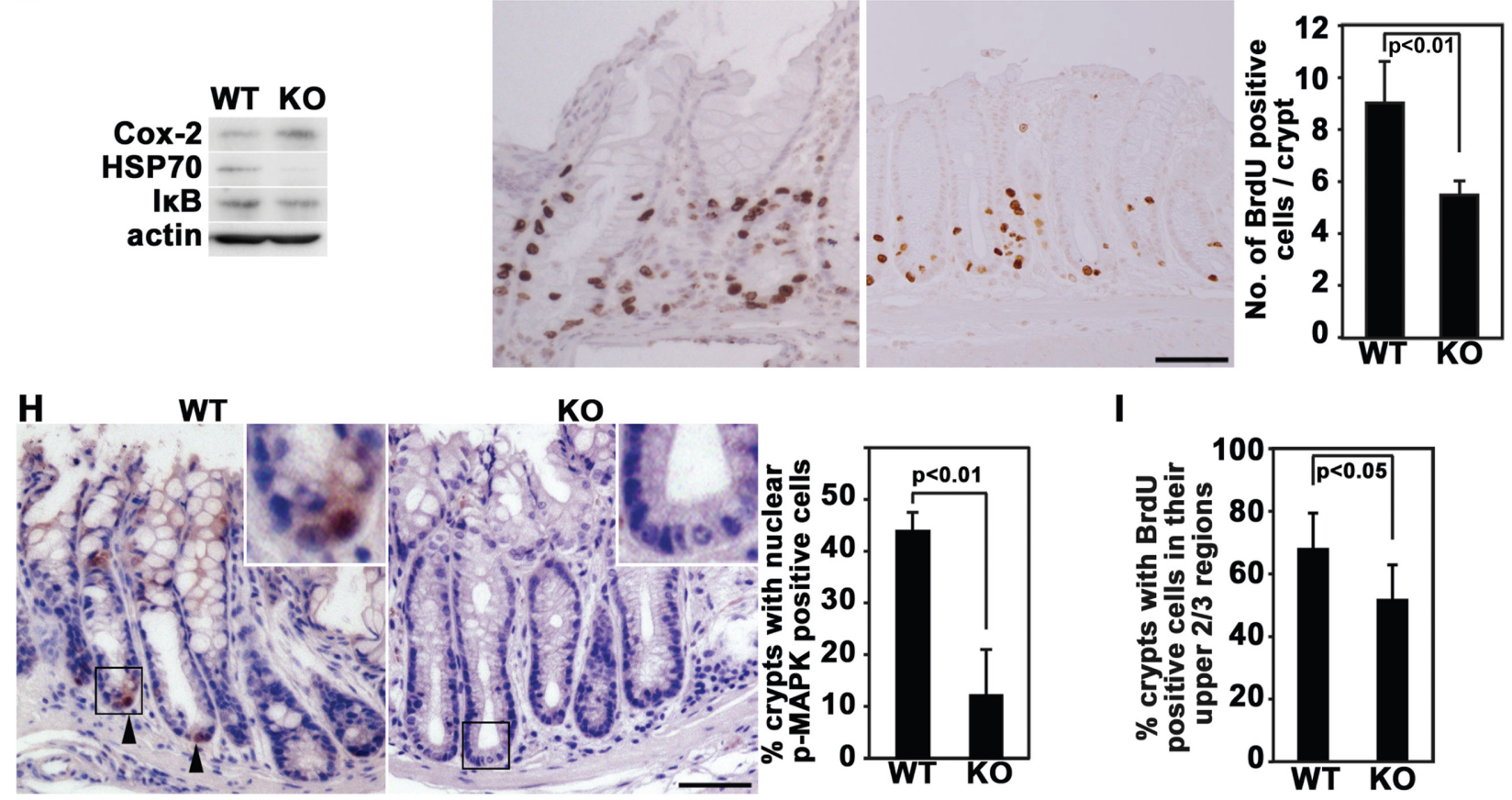

I

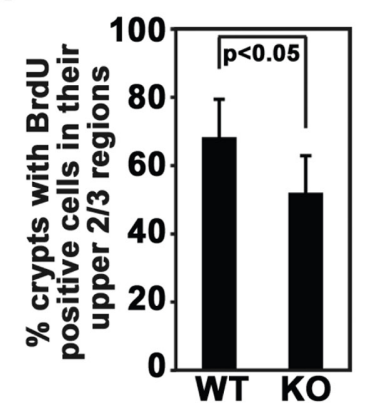

Fig. 1.

covery following DSS treatment. Ki-67-positive proliferating cells was reduced in $\mathrm{Noxl}^{-/ Y}$ mice compared with WT controls (Fig. 1F), suggesting that Nox 1 is required for proliferation of progenitor cells. To further confirm this, the frequency of BrdU-labeled growing cells was examined. Similar to the result obtained by Ki-67 staining, the colonic crypt of Noxl $^{-/ Y}$ mice showed a markedly decreased number of BrdU-labeled proliferating cells (Fig. 1G). As Nox1 drives the growth factor receptor-coupled MEK/Erk signaling pathway in growing 
colon cancer cells [10], we therefore analyzed whether this signaling cascade is regulated by Nox 1 in the recovering intestinal epithelium. Phosphorylation of Erk at Tyr-204/Thr-202 residues was dramatically suppressed by Nox 1 deletion, indicating that Nox1-controlled proliferation of progeny cells possibly involves Erk (Fig. 1H). Notably, Ki-67-stained cells were present even in the middle regions of crypts in WT mice, in contrast to Nox $1^{-/ Y}$ mice (Fig. 1F). The number of crypts with BrdUlabeled cells present in their upper 2/3 regions was lower in Nox $1^{-/ Y}$ mice than WT controls (Fig. 1I). Since these crypt regions are remote from the stem cells and considered to be differentiated and nonproliferating [23], the data suggest that BrdU-incorporated cells rapidly migrated from the stem cell area and that Nox 1 deficiency suppressed their migration. Thus, Nox1 deletion inhibited both proliferation and migration of progenitor cells along the crypt axis. Consistently, we previously demonstrated the mediating role of Nox 1 in both proliferation and migration of colon cancer cells $[6,24]$.

\section{Effects of Nox1 deletion on goblet cell differentiation and colonal cell viability}

To further investigate the involvement of Nox 1 in colon mucosal healing, differentiation of goblet cells was evaluated with the expression of acidic, neutral, and Muc2 mucins by using Alcian Blue (AB), Periodic acidSchiff (PAS), and anti-Muc2 antibodies, respectively. Without DSS treatment, neither AB-PAS nor Muc2 stain- ing differed between WT and $\mathrm{Noxl}^{-/ Y}$ mice (Figs. 2A and 2B). After DSS withdrawal, strikingly, the colon of DSStreated $\mathrm{NoxI}^{-/ Y}$ mice exhibited a reduction in both mucin staining and goblet cell number compared with those in DSS-treated control littermates (Figs. 2A and 2B), suggesting that Nox 1 deficiency causes a lack of maturation in goblet cells. In addition, the effect of Nox1 deletion on the survival activity of colon epithelial cells was examined by TUNEL assay, because Nox isozymes including Nox4 have previously been shown to protect cells from apoptosis in various biological systems [7]. The number of TUNEL-positive cells was higher in Noxl $^{-/ Y}$ crypts compared with that in WT controls after 5 days of recovery from colitis (Fig. 2C), suggesting that Nox1 sustains cell viability in the colon epithelium.

\section{Upregulation of Noxl and ROS production during restitution following colitis}

To further assess the association of Nox 1 with the repair process, we investigated the expression of Nox1 in colon tissues during recovery from colitis. The effect of Nox 1 deletion on superoxide production was first examined by using the fluorescent probe Hydro-Cy3, which is a hydrocyanine derivative and highly sensitive to ROS [9]. A substantial level of ROS production was observed in WT crypts following colitis, whereas it was diminished in their Noxl $^{-/ Y}$ counterparts (Fig. 3A). To determine whether ROS production correlates with the expression level of Nox1, the Nox1 expression was ex-

Fig. 1. Inhibition of Nox 1 suppresses recovery from DSS-induced colitis, which is accompanied by decreased growth and migration of colonic cells. (A) Representative pictures of colon tissues on day 9 in WT mice with and without administration of DSS, followed by recovery from colitis. Colon sections were stained with $\mathrm{H} \& \mathrm{E}$. The lengths of the analyzed colons were $6 \mathrm{~cm}$ and 4.5 $\mathrm{cm}$ for DSS-treated and DSS-untreated mice, respectively. (B and C) WT control and Nox $1^{-/ Y}$ mice were given DSS (B). Alternatively, WT mice were given DSS together with DPI or DMSO (C). Then, the animals were allowed to recover from colitis. Histological damage was quantified by estimating the percentage of intact crypts found within an entire section of the colon (4.5 to $6 \mathrm{~cm}$ length). Histograms represent mean $\pm \mathrm{SD}$ values $\left[\mathrm{n}=12\right.$ for $\mathrm{WT}$ and $N o x 1^{-/ Y}$ mice (B) and $\mathrm{n}=5$ for DMSO and DPI-

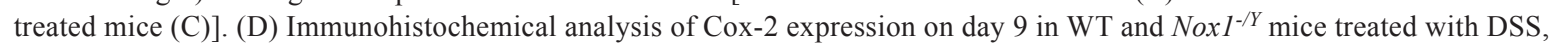
followed by recovery from colitis in the colon. Histograms represent the percentages of Cox-2-positive cells found within 0.1 $\mathrm{mm}^{2}$ sections of colons (mean $\pm \mathrm{SD}, \mathrm{n}=5$ for WT and Nox $1^{-/ Y}$ mice). (E) Immunoblotting analysis of Cox-2, HSP70, and I $\mathrm{kB}$ expression in the colon. Colonic extracts were prepared from WT and Nox $1{ }^{\mathrm{KO}}$ mice at 5 days after termination of DSS administration. $\beta$-actin was used as a loading control. (F) WT and $N o x 1^{-/ Y}$ mice were treated with $2 \%$ DSS and allowed to recover from colitis. Colon sections were stained with anti-Ki-67 antibodies. Histograms represent the number of Ki-67-positive cells per crypt (mean $\pm \mathrm{SD}, \mathrm{n}=5$ for WT and Nox $1^{-/ Y}$ mice). (G) WT and Nox $1^{-/ Y}$ mice were treated with DSS and allowed to recover from colitis. Colon sections were prepared following administration of BrdU $2 \mathrm{~h}$ prior to sacrifice and stained with anti-BrdU antibodies. Histograms represent the number of BrdU-positive cells per crypt (mean $\pm \mathrm{SD}, \mathrm{n}=5$ for WT and Nox $1^{-/ Y}$ mice). (H) WT and Nox $1^{-/ Y}$ mice were treated with DSS and allowed to recover as in Fig. 1A. Colon sections were stained with anti-phospho-MAPK (Erk) Thr-202/Tyr-204 antibodies. (Insert): magnification x3.5. Histograms represent the percentage of crypts with nuclear phospho-MAPK-positive cells (arrowheads) per 30 crypts (mean $\pm \mathrm{SD}, \mathrm{n}=5$ for WT and $N o x 1^{-/ Y}$ mice). (I) WT and Nox $1^{-/ Y}$ mice were treated with DSS, allowed to recover from colitis, administered BrdU, $2 \mathrm{~h}$ before sacrifice, and stained with anti-BrdU antibodies. Histograms represent the percentage of crypts with BrdU-positive cells in their upper $2 / 3$ regions per 20 crypts (mean $\pm \mathrm{SD}, \mathrm{n}=5$ for WT and Nox $^{-/ Y}$ mice. Scale bar $=50 \mu \mathrm{m}$. 


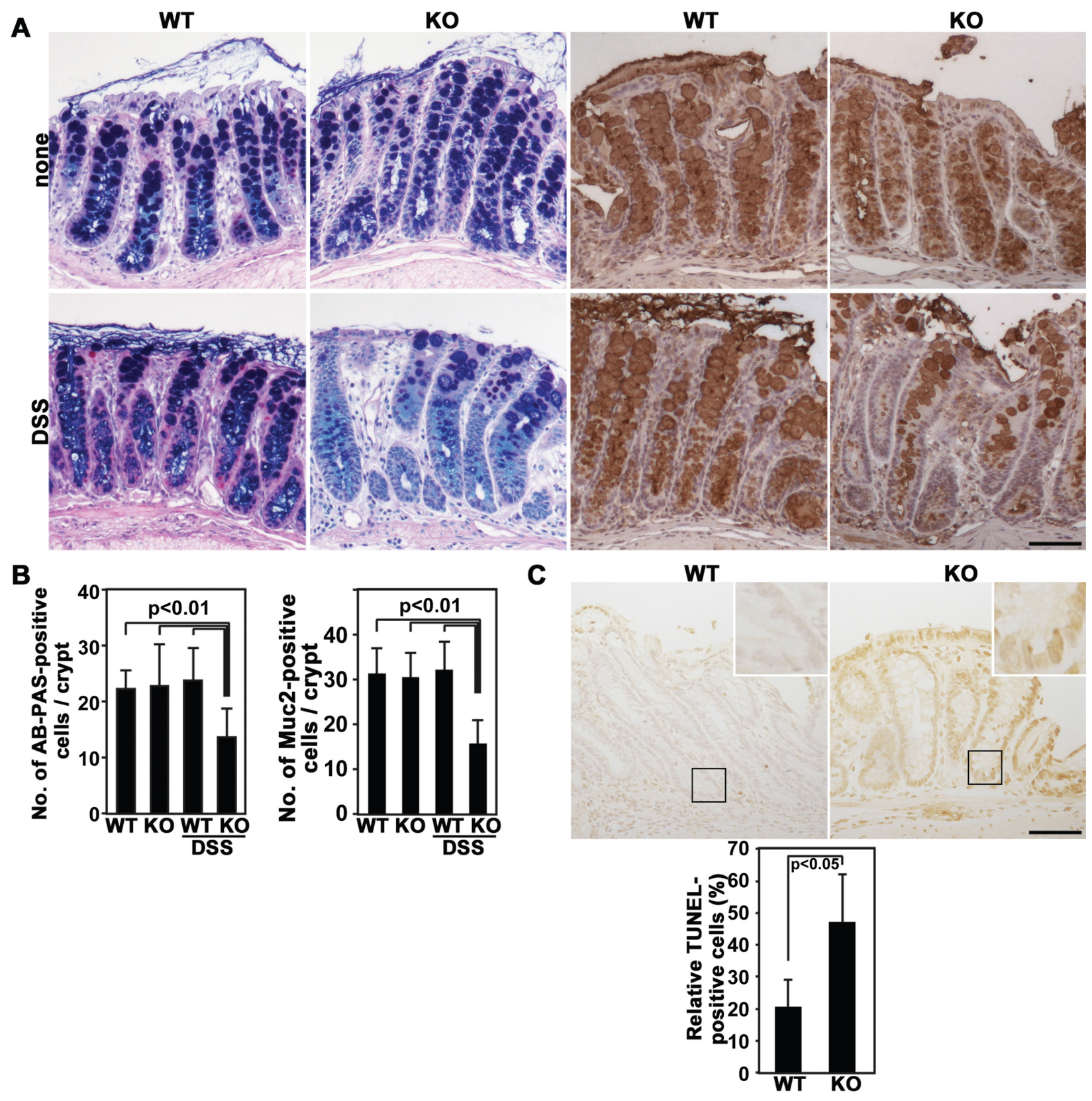

Fig. 2. Goblet cell differentiation and survival of colonic cells during recovery from colitis. (A and B) Colon sections prepared from WT and Noxl $^{-/ Y}$ mice at day 5 after termination of DSS administration were stained with AB-PAS (dark blue) or anti-Mucin 2 (brown) antibodies (A). Histograms represent the number of AB-PAS-stained cells or Mucin 2-positive per crypt (mean \pm SD, $\mathrm{n}=5$ for WT and Nox $^{-/ Y}$ ) (B). (C) TUNEL staining of colon tissue from WT and Nox $1^{-/ Y}$ mice 5 days after termination of DSS administration. (Insert): magnification x3.5. Histograms represent the ratios of TUNEL-positive cells (arrowhead) within 0.1 $\mathrm{mm}^{2}$ sections of crypts $\left(\right.$ mean $\pm \mathrm{SD}, \mathrm{n}=5$ for WT and Noxl $\left.^{-/ Y}\right)$. Scale bar $=50 \mu \mathrm{m}$.

amined by immunostaining with a monoclonal antibody to Nox1, which has been shown to specifically recognize Nox1 proteins [1,27]. Increased Nox1 was detected in the apical membrane of colon epithelial cells in WT mice, but it was undetectable in the same areas in Nox $^{-}$ ${ }^{/ Y}$ mice (Fig. 3B). The results suggest that Nox 1 is indeed responsible for ROS generation in the colon epithelial cells and exerts its biological role through ROS signaling. Furthermore, both the Nox1 level (Fig. 3B) and Ki-67-positive cells (Fig. 3C) significantly increased in DSS-treated WT mice compared with untreated controls during the recovery period, confirming the upregulation 
A

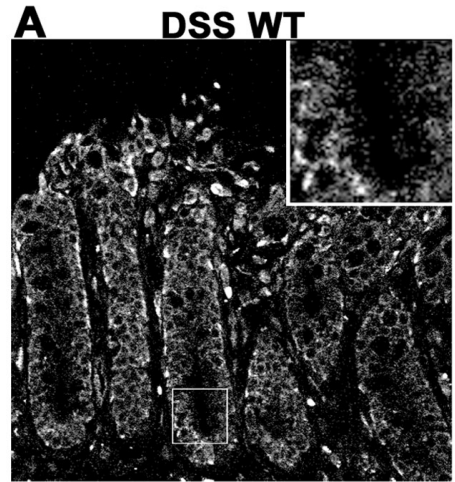

B

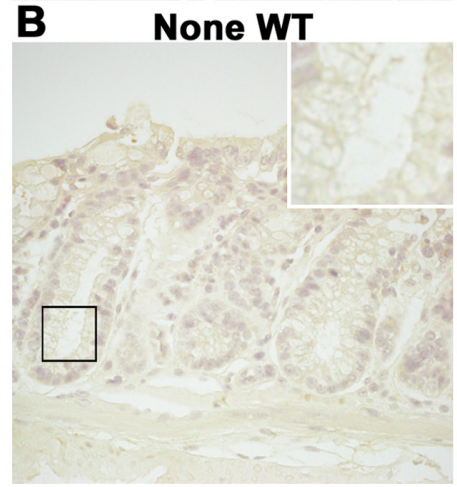

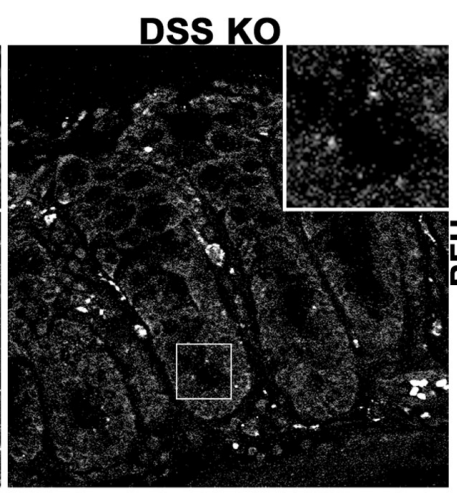

DSS WT

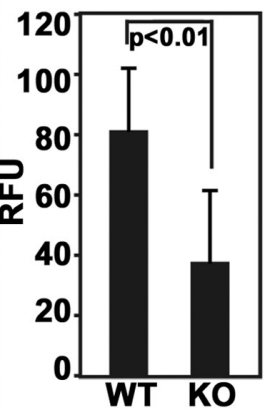

DSS KO

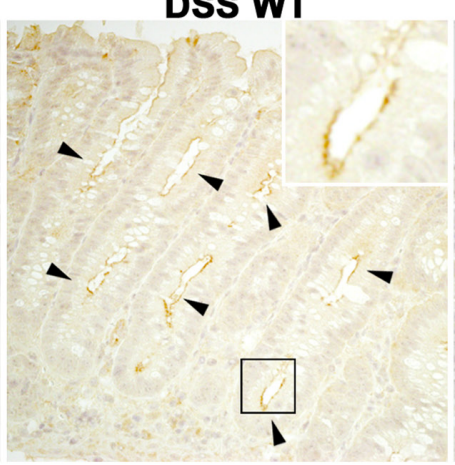

C
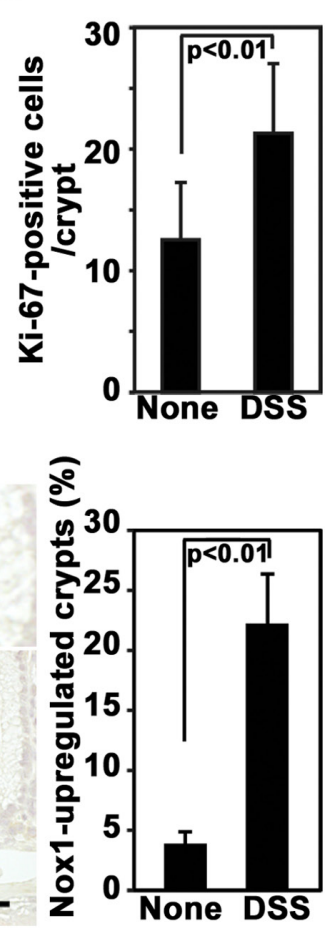

Fig. 3. Both Nox 1 and ROS levels are increased during restitution from colitis. (A) Representative confocal fluorescent images of colon sections. Colons obtained from WT and Noxl $1^{-Y Y}$ mice at day 5 after termination of DSS administration were labeled with $25 \mu \mathrm{M}$ Hydro-CY3. (Insert): magnification $\times 3.5$. Histograms represent the relative intensity of fluorescence per crypt $(\mathrm{mean} \pm \mathrm{SD}, \mathrm{n}=20$ for WT and Noxl $^{-/ Y}$ mice). (B) WT mice were treated with or without DSS, and Nox1 ${ }^{-/ Y}$ mice were treated with DSS, followed by recovery from colitis. Colon sections were stained with anti-Nox1 antibodies. Arrowheads indicate the Nox 1 expression in colon epithelial cells. (Insert): magnification $\times 3.5$. Histograms represent the percentage of Nox1-upregulated crypts found in 20 crypts in WT mice (mean $\pm \mathrm{SD}, \mathrm{n}=8$ for WT mice). (C) WT mice were treated with or without DSS and allowed to recover from colitis. Colon sections were stained with anti-Ki-67 antibodies. Histograms represent the number of Ki-67-positive cells per crypt (mean $\pm \mathrm{SD}, \mathrm{n}=8$ for WT mice). Scale bar $=50 \mu \mathrm{m}$.

of Nox1 and concomitant increased cell growth during epithelial restitution. These results are consistent with the notion that Nox1 facilitates mucosal repair by sustaining the bioactivity of progenitor cells.

\section{Discussion}

Colon epithelial homeostasis is dysregulated in inflammatory bowel diseases, including ulcerative colitis, and renewal of the damaged colon epithelium is tightly regulated by cellular processes, such as proliferation, differentiation, migration, and cell death of the epithelial cells. On the other hand, little is known about the exact physiological role of Nox 1 in the colon, although it has been speculated that Nox 1 provides an oxidative host defense barrier against intestinal pathogens [3]. The results presented here suggest a required role of Nox 1 in epithelial restitution from colitis. Our study using genetically engineered $\mathrm{Noxl}^{-/ Y}$ mice showed that Nox1 deficiency significantly delayed recovery from experimental mucosal injury. This aberrant repair process was accompanied by suppression of both proliferation and migration of transit progenitor cells derived from colon stem cells. Nox 1 deletion also attenuated differentiation of progenitor cells into mucus-secreting goblet cells and the survival activity of colonocytes. Thus, we propose that Nox1 plays a critical mediating role in restitution from colon epithelial injury, contributing to restoration of intestinal homeostasis.

ROS are involved in the regulation of proliferation and differentiation of embryonic stem cells and are also considered to act as a second messenger in several selfrenewing tissue cells including hematopoietic stem cells, neural stem cells, and spermatogonial stem cells [18]. Our finding that ROS generated by the epithelial Nox1 maintain the bioactivity of committed progenitor cells 
during repair of colonic epithelial injury is consistent with this viewpoint, emphasizing the importance of Nox1-derived ROS in self-renewal of the colonic epithelium. In the present study, the effect of Nox 1 deletion on differentiation status was examined with goblet cells but not other colon epithelial constituents such as M-cells and Paneth cells. Since all colon epithelial cell lineages develop from epithelial stem cells within the crypt [15], it is most likely the case that Nox1 regulates the differentiation of these cells, as in the case of goblet cells. On the other hand, in Nox1 deficiency, mice have a normal colonic mucosa with functional goblet cells as in WT mice (Fig. 2A), and the healing of damage induced by DSS treatment is not inhibited completely. These findings suggest that several signaling pathways, including the Nox1 pathway, contribute to the differentiation.

Of note, upregulation of Nox1 proteins was induced in colon cryptic cells from DSS-treated mice (Fig. 3B), resulting in elevated ROS production. The underlying mechanism for this event is currently unknown. One possibility is that upon disruption of the epithelial barrier by DSS, cytokines or growth factors are released from infiltrating immune cells and thereby activate the gene expression of Nox1. In fact, Nox1 expression has been reported to be induced by TNF $\alpha$ [20], PDGF [13], and EGF [17].

Previous studies suggested a critical role for Nox 1 as a signal transducer controlling cell proliferation and fate in the colon epithelium: Nox 1 contributes to maintenance of basal intestinal homeostasis [2], and its deficiency, combined with the lack of IL-10, caused ulcerative colitis in mice [26]. However, the studies did not address the Nox1 function in repair following epithelial injury and colitis. Thus, our discovery has a significant implication in the sense that it revealed for the first time the Nox1-based redox regulation of the proliferative phase of tissue remodeling following colonic inflammation. The involvement of Nox1 in mucosal wound repair has recently been reported in other biological systems as well: Annexin A1, the endogenous FPR ligand secreted in the mucosal layer, promoted migration of intestinal epithelial cells through activation of FPR- and Nox1dependent redox signaling, leading to wound closure in the intestinal epithelium [14]. This observation together with our observations suggests that Nox1 oxidase-derived ROS are critically involved in the redox balance responsible for the regulation of tissue remodeling.

In conclusion, we showed the role of Nox 1 expression in mucosal repair following colitis and identified Nox 1 as an integral component of the machinery required for maintenance of colon physiology. Further study will be of great interest in determining which downstream signaling pathway (s) Nox 1-generated ROS target and how they modulate the signaling events.

\section{Acknowledgments}

Financial support for this work was provided by a Grant-in-Aid for Scientific Research from the Japan Society for the Promotion of Science (22300328, to T.K.) and a Grant for Scientific Research from Nagano Society for the Promotion of Science (to M.K.).

\section{Reference}

1. Chen, W., Shang, W.H., Adachi, Y., Hirose, K., Ferrari, D.M., and Kamata, T. 2008. A possible biochemical link between NADPH oxidase (Nox) 1 redox-signalling and ERp72. Biochem. J. 416: 55-63. [Medline] [CrossRef]

2. Coant, N., Ben Mkaddem, S., Pedruzzi, E., Guichard, C., Tréton, X., Ducroc, R., Freund, J.N., Cazals-Hatem, D., Bouhnik, Y., Woerther, P.L., Skurnik, D., Grodet, A., Fay, M., Biard, D., Lesuffleur, T., Deffert, C., Moreau, R., Groyer, A., Krause, K.H., Daniel, F., and Ogier-Denis, E. 2010. NADPH oxidase 1 modulates WNT and NOTCH1 signaling to control the fate of proliferative progenitor cells in the colon. Mol. Cell. Biol. 30: 2636-2650. [Medline] [CrossRef]

3. Geiszt, M., Lekstrom, K., Brenner, S., Hewitt, S.M., Dana, R., Malech, H.L., and Leto, T.L. 2003. NAD(P)H oxidase 1, a product of differentiated colon epithelial cells, can partially replace glycoprotein 91phox in the regulated production of superoxide by phagocytes. J. Immunol. 171: 299-306. [Medline] [CrossRef]

4. Harada, O., Suga, T., Suzuki, T., Nakamoto, K., Kobayashi, M., Nomiyama, T., Nadano, D., Ohyama, C., Fukuda, M.N., and Nakayama, J. 2007. The role of trophinin, an adhesion molecule unique to human trophoblasts, in progression of colorectal cancer. Int. J. Cancer 121: 1072-1078. [Medline] [CrossRef]

5. Ibi, M., Matsuno, K., Shiba, D., Katsuyama, M., Iwata, K., Kakehi, T., Nakagawa, T., Sango, K., Shirai, Y., Yokoyama, T., Kaneko, S., Saito, N., and Yabe-Nishimura, C. 2008. Reactive oxygen species derived from NOX1/NADPH oxidase enhance inflammatory pain. J. Neurosci. 28: 9486-9494. [Medline] [CrossRef]

6. Kajla, S., Mondol, A.S., Nagasawa, A., Zhang, Y., Kato, M., Matsuno, K., Yabe-Nishimura, C., and Kamata, T. 2012. A crucial role for Nox 1 in redox-dependent regulation of Wnt$\beta$-catenin signaling. FASEB J. 26: 2049-2059. [Medline] [CrossRef]

7. Kamata, T. 2009. Roles of Nox 1 and other Nox isoforms in cancer development. Cancer Sci. 100: 1382-1388. [Medline] [CrossRef] 
8. Kikuchi, H., Hikage, M., Miyashita, H., and Fukumoto, M. 2000. NADPH oxidase subunit, gp91(phox) homologue, preferentially expressed in human colon epithelial cells. Gene 254: 237-243. [Medline] [CrossRef]

9. Kim, J.Y., Choi, W.I., Kim, Y.H., and Tae, G. 2011. Highly selective in-vivo imaging of tumor as an inflammation site by ROS detection using hydrocyanine-conjugated, functional nano-carriers. J. Control. Release 156: 398-405. [Medline] [CrossRef]

10. Komatsu, D., Kato, M., Nakayama, J., Miyagawa, S., and Kamata, T. 2008. NADPH oxidase 1 plays a critical mediating role in oncogenic Ras-induced vascular endothelial growth factor expression. Oncogene 27: 4724-4732. [Medline] [CrossRef]

11. Lambeth, J.D. 2004. NOX enzymes and the biology of reactive oxygen. Nat. Rev. Immunol. 4: 181-189. [Medline] [CrossRef]

12. Lambeth, J.D. 2007. Nox enzymes, ROS, and chronic disease: an example of antagonistic pleiotropy. Free Radic. Biol. Med. 43: 332-347. [Medline] [CrossRef]

13. Lassègue, B., Sorescu, D., Szöcs, K., Yin, Q., Akers, M., Zhang, Y., Grant, S.L., Lambeth, J.D., and Griendling, K.K. 2001. Novel gp91(phox) homologues in vascular smooth muscle cells : nox1 mediates angiotensin II-induced superoxide formation and redox-sensitive signaling pathways. Circ. Res. 88: 888-894. [Medline] [CrossRef]

14. Leoni, G., Alam, A., Neumann, P.A., Lambeth, J.D., Cheng, G., McCoy, J., Hilgarth, R.S., Kundu, K., Murthy, N., Kusters, D., Reutelingsperger, C., Perretti, M., Parkos, C.A., Neish, A.S., and Nusrat, A. 2013. Annexin A1, formyl peptide receptor, and NOX1 orchestrate epithelial repair. J. Clin. Invest. 123: 443-454. [Medline] [CrossRef]

15. Mabbott, N.A., Donaldson, D.S., Ohno, H., Williams, I.R., and Mahajan, A. 2013. Microfold (M) cells: important immunosurveillance posts in the intestinal epithelium. Mucosal Immunol. 6: 666-677. [Medline] [CrossRef]

16. Matsuno, K., Yamada, H., Iwata, K., Jin, D., Katsuyama, M., Matsuki, M., Takai, S., Yamanishi, K., Miyazaki, M., Matsubara, H., and Yabe-Nishimura, C. 2005. Nox1 is involved in angiotensin II-mediated hypertension: a study in Nox1deficient mice. Circulation 112: 2677-2685. [Medline] [CrossRef]

17. Mitsushita, J., Lambeth, J.D., and Kamata, T. 2004. The superoxide-generating oxidase Nox 1 is functionally required for Ras oncogene transformation. Cancer Res. 64: 35803585. [Medline] [CrossRef]

18. Mohyeldin, A., Garzón-Muvdi, T., and Quiñones-Hinojosa, A. 2010. Oxygen in stem cell biology: a critical component of the stem cell niche. Cell Stem Cell 7: 150-161. [Medline] [CrossRef]
19. Mochizuki, T., Furuta, S., Mitsushita, J., Shang, W.H., Ito, M., Yokoo, Y., Yamaura, M., Ishizone, S., Nakayama, J., Konagai, A., Hirose, K., Kiyosawa, K., and Kamata, T. 2006. Inhibition of NADPH oxidase 4 activates apoptosis via the AKT/apoptosis signal-regulating kinase 1 pathway in pancreatic cancer PANC-1 cells. Oncogene 25: 3699-3707. [Medline] [CrossRef]

20. Mouzaoui, S., Djerdjouri, B., Makhezer, N., Kroviarski, Y., El-Benna, J., and Dang, P.M. 2014. Tumor necrosis factor$\alpha$-induced colitis increases NADPH oxidase 1 expression, oxidative stress, and neutrophil recruitment in the colon: preventive effect of apocynin. Mediators Inflamm. 2014: 312484. [Medline] [CrossRef]

21. Neurath, M.F., Fuss, I., Kelsall, B.L., Stüber, E., and Strober, W. 1995. Antibodies to interleukin 12 abrogate established experimental colitis in mice. J. Exp. Med. 182: 1281-1290. [Medline] [CrossRef]

22. Okayasu, I., Hatakeyama, S., Yamada, M., Ohkusa, T., Inagaki, Y., and Nakaya, R. 1990. A novel method in the induction of reliable experimental acute and chronic ulcerative colitis in mice. Gastroenterology 98: 694-702. [Medline]

23. Rakoff-Nahoum, S., Paglino, J., Eslami-Varzaneh, F., Edberg, S., and Medzhitov, R. 2004. Recognition of commensal microflora by toll-like receptors is required for intestinal homeostasis. Cell 118: 229-241. [Medline] [CrossRef]

24. Shinohara, M., Adachi, Y., Mitsushita, J., Kuwabara, M., Nagasawa, A., Harada, S., Furuta, S., Zhang, Y., Seheli, K., Miyazaki, H., and Kamata, T. 2010. Reactive oxygen generated by NADPH oxidase 1 (Nox1) contributes to cell invasion by regulating matrix metalloprotease- 9 production and cell migration. J. Biol. Chem. 285: 4481-4488. [Medline] [CrossRef]

25. Simons, B.D. and Clevers, H. 2011. Stem cell self-renewal in intestinal crypt. Exp. Cell Res. 317: 2719-2724. [Medline] [CrossRef]

26. Tréton, X., Pedruzzi, E., Guichard, C., Ladeiro, Y., Sedghi, S., Vallée, M., Fernandez, N., Bruyère, E., Woerther, P.L., Ducroc, R., Montcuquet, N., Freund, J.N., Van Seuningen, I., Barreau, F., Marah, A., Hugot, J.P., Cazals-Hatem, D., Bouhnik, Y., Daniel, F., and Ogier-Denis, E. 2014. Combined NADPH oxidase 1 and interleukin 10 deficiency induces chronic endoplasmic reticulum stress and causes ulcerative colitis-like disease in mice. PLOS ONE 9: e101669. [Medline] [CrossRef]

27. Zhang, Y., Nakayama, J., and Kamata, T. 2015. Nox4-generated ROS regulate TGF- $\beta 1$-induced motility of colon cancer cells through the low molecular weight protein tyrosine phosphatase-Rho signaling pathway. Shinshu Med. J. 63: 281-293. 